\title{
Key Issues in Industrial Growth in Pakistan
}

\section{A. R. Kemal*}

\begin{abstract}
The author here looks at problems in the manufacturing sector. One macro enigma is that while growth had recently risen to 8\%, investment levels as a ratio of GDP seem to have fallen. One reason for this is the re-evaluation upwards of the GDP. But the same issue emerges in manufacturing with very high growth rates coinciding with falling investment levels. The declining investment levels could be due to a number of factors including high production costs, transaction costs, policy continuity risks, skills and wages and changes in the demand structure.
\end{abstract}

\section{Introduction}

Over the last couple of years the manufacturing sector has grown at the rates of 14.1 and 12.5 percent and large scale manufacturing at even more rapid rates of 18.2 and 15.4 percent $^{1}$. These growth rates are more than twice the growth rate of the first three years of the present decade and more than three times those observed in the 1990s. On the other hand investment in the manufacturing sector during the two years has declined at a rate of 2.6 percent- 8.5 percent growth in 2003-04 and 12.6 percent decline in 2004-05. As a percentage of GDP investment increased from 3.2 percent in 1999-2000 to 3.6 percent in 2003-04 but declined sharply to 2.9 percent in 2004-05. The low levels of investment cast serious doubts on the sustainability of growth rates of manufacturing output. The low and fluctuating rate of investment is a cause for concern and has been responsible for the slow and fluctuating growth of the manufacturing sector.

The manufacturing sector of Pakistan suffers from various structural problems resulting in slow growth rates of investment, output, and exports. These include among others lack of diversification, allocative, technical and X-inefficiencies, poor quality of products, and low levels of $\mathrm{R} \& \mathrm{D}$ activities resulting in slow growth rates of productivity making

\footnotetext{
${ }^{*}$ Former Director, Pakistan Institute of Development Economics, Islamabad.

${ }^{1}$ During the first quarter of the current year the large scale manufacturing sector has grown at a rate of around 8 percent.
} 
Pakistani products uncompetitive in the world market. The traditional industries such as food and textile industries still account for an overwhelming share of the manufacturing output; food industries accounted for 13.8 and textiles for 24.0 percent of the total manufacturing value added in 2000-01. On the other hand industries based on modern technologies such as electrical and non-electrical machinery and automobile industries accounted for just 4.4 and 4.7 percent of value added respectively. Even though chemical industries accounted for around 15.2 percent of manufacturing output ${ }^{2}$, most of the chemical industrial output is concentrated in low-tech and low value added industries ${ }^{3}$.

Because of high protection rates, value added of the manufacturing sector at world prices has been just a fraction of that at domestic market prices. The productivity levels in most of the manufacturing industries continue to be low, making it increasingly difficult for Pakistani producers to compete in the world market. Low quality of products, lack of standardization, low value added products sold without any brand names, lack of innovation, and low levels of productivity are the legacy of import substitution industrialization and indicate the need for major restructuring of the manufacturing sector.

Why are entrepreneurs still reluctant to invest, which limits productivity and competitiveness of the manufacturing sector? Is it due to low levels of profitability resulting from higher production costs or it is due to their perception that the policies may change with serious implications for long run profitabilities? Is the cost of production high due to the production, technical, allocative and X-inefficiencies or is it due to the high cost of inputs, both traded and non-traded? Are transaction costs high in the country and the procedures cumbersome, and government attitude manifested in tax administration, labor inspectorate and non-investment friendly attitude of various government departments? Or is it due to poor skills and high wages adjusted for productivity levels that is constraining investments? Or are fluctuations in manufacturing output due to changes in the demand pattern? This paper attempts to examine these issues and suggests policy measures for sustaining a high growth rate in the manufacturing sector.

The plan of the paper is as follows. After this introductory section, the growth rates and patterns of industrial growth are examined in section

\footnotetext{
${ }^{2}$ The chemical sector is defined as the industries producing pharmaceutical products, industrial and other chemicals. Their share in the manufacturing value added in 2000-01 is 4.3, 9.2 and 1.7 percent respectively. It does not include petroleum refining, rubber and plastic products.

${ }^{3}$ Pharmaceutical industries are just a packaging industry, and the other chemical industry except fertilizer is just formulation based on the imported compounds.
} 
2. The main problems faced by the producers are examined in section 3. A strategy for rapid and efficient growth of the large scale manufacturing sector in the perspective of the strategy outlined in the Medium Term Development Framework is described in section 4. Main conclusions are summarized in the concluding section of the paper.

\section{Trends in Growth and Patterns of the Manufacturing Sector}

Starting from virtually scratch at the time of independence, Pakistan has made significant advances in the manufacturing sector. A handful of industrial units producing sugar, vegetable ghee, tea blending, cement and cotton textiles comprised the total large scale industrial assets of Pakistan at the time of independence and contributed only 1.8 percent to GDP. The small-scale industries however, contributed 4.6 percent to GDP. While the share of small-scale industries has increased to only 5.6 percent, the share of large scale industries ${ }^{4}$ increased to 12.7 percent by the year 2004-05. The share of the manufacturing sector in GDP has increased from 6.4 percent in $1949-50$ to 18.3 percent in $2004-05$.

Table-1: Percentage Shares of Manufacturing Sector in GDP

\begin{tabular}{cccc}
\hline & Total & Large Scale & Small Scale \\
\hline $1949-50$ & 6.39 & 1.83 & 4.56 \\
$1959-60$ & 9.91 & 5.67 & 4.23 \\
$1969-70$ & 13.44 & 10.46 & 2.98 \\
$1979-80$ & 14.51 & 10.55 & 3.95 \\
$1989-90$ & 17.59 & 12.70 & 4.89 \\
$1999-2000$ & 16.66 & 11.65 & 5.03 \\
$1999-2000$ & 14.81 & 9.59 & 5.22 \\
$2000-01$ & 15.90 & 10.45 & 5.45 \\
$2001-02$ & 16.11 & 10.49 & 5.62 \\
$2002-03$ & 16.42 & 10.73 & 5.69 \\
$2003-04$ & 17.60 & 11.92 & 5.68 \\
$2004-05$ & 18.26 & 12.70 & 5.56 \\
\hline
\end{tabular}

Source: 50 Years of Pakistan Volume I Summary, Pakistan Economic Survey, various issues.

\footnotetext{
${ }^{4}$ The National Accounts base has been changed to 1999-2000 and the share of small and large-scale manufacturing in 2002-03 according to a new base has been 10.7 and 4.2 percent and in 2003-04 increased to 11.8 and 4.3 percent, respectively.
} 
Over the 1950-2005 period the manufacturing sector has grown at a rate of 7.5 percent, and the large and small scale manufacturing industries at rates of 9.2 and 5.5 percent. However, the average growth rate of the manufacturing industries conceals wide fluctuations across decades and within each of the decades. For example, rather high growth rates were observed in the 1950s, 1960s, and 1980s and over the last few years and relatively low growth rates in the 1970s and 1990s.

Manufacturing industries grew at a rate of 7.7 percent during the 1950 s and the large-scale industries at a phenomenal rate of 15.8 percent. The industrial policy during the period aimed at manufacturing the products based on indigenous raw materials such as cotton, jute, hides, and skins, for which there was an assured market at home and abroad, and developing the consumer goods industries to meet the requirements of the home market for which the country was heavily dependent on imports. The two main characteristics of the policies during the 1950s have been direct controls on imports, investment, prices etc., and a large anti-export bias.

Table-2: Growth Rates of Manufacturing Sector

\begin{tabular}{cccc}
\hline \multirow{2}{*}{ Year } & \multicolumn{3}{c}{ Manufacturing Sector } \\
\cline { 2 - 4 } & Total & Large Scale & Small Scale \\
\hline $1950 \mathrm{~s}$ & 7.73 & 15.75 & 2.30 \\
$1960 \mathrm{~s}$ & 9.91 & 13.39 & 2.91 \\
$1970 \mathrm{~s}$ & 5.50 & 4.84 & 7.63 \\
$1980 \mathrm{~s}$ & 8.21 & 8.16 & 8.40 \\
$1990 \mathrm{~s}$ & 3.88 & 3.54 & 5.06 \\
$2001-05$ & 9.38 & 10.94 & 6.25 \\
$2000-01$ & 9.28 & 10.95 & 6.22 \\
$2001-02$ & 4.46 & 3.51 & 6.29 \\
$2002-03$ & 6.90 & 7.22 & 6.30 \\
$2003-04$ & 14.06 & 18.22 & 6.20 \\
$2004-05$ & 15.42 & 12.47 & 6.25 \\
$1950-2005$ & 7.53 & 9.21 & 5.32 \\
\hline
\end{tabular}

Source: 50 Years of Pakistan Volume I Summary, Pakistan Economic Survey, various issues. 
Growth of the manufacturing sector accelerated even further to 9.91 percent during the 1960s. A number of initiatives helped in realizing the high growth rate, which included a liberal import policy, subsidy to exports through a number of schemes such as Export Bonus Scheme, tax rebates, tax exemption, Export Performance Licensing, and Pay-As-You-Earn Schemes. Protection rates in the period were rather high resulting in excessive profits for the producers. Moreover, tax holidays and accelerated depreciation allowances further increased the post-tax profits of the manufacturing industries.

The growth rate of the manufacturing sector fell to 5.50 percent and for large scale manufacturing to just 4.84 percent during the 1970s. The most important initiative was the nationalization of heavy industry and a number of sectors including cement, fertilizer, oil refining, engineering, and chemicals, which were exclusively reserved for the public sector and the policy of divesting profitable public sector units was discontinued. Moreover, the industrialists faced a number of restrictions including price controls by the government under the Profiteering and Hoarding Act. These measures created a considerable amount of uncertainty, resulting in a fall in private investment and flight of capital. Moreover, these policies had long run implications for the industrialization process manifested in the reluctance of the private sector to invest, which continues to date.

During the 1980s the process of de-regulation, de-control and denationalization was initiated and various measures were taken to restore the confidence of investors. Administrative controls were replaced with market-oriented forces: the import policy was liberalized, and the tariff structure was rationalized, the par value of the rupee was brought nearer to its equilibrium value and it was made convertible on the capital account, investment licensing was abolished, prices were de-controlled, and the performance of public enterprises improved due to the signaling system. The market friendly policies resulted in acceleration of the growth rate to 8.21 percent.

While the process of deregulation continued and a large number of manufacturing public enterprises were privatized, the growth rate decelerated to 3.88 percent in the 1990s. The performance of large-scale manufacturing was even more disappointing which grew at a rate of only 3.54 percent. A number of economic and non-economic factors have been responsible for the deceleration of growth. Prominent factors have been political instability, worsening of the law and order situation in the major growth poles of the country, reduction in protection rates resulting in the closure of a number of industries, emergence of significant infrastructural 
bottlenecks in transport and other sectors, inadequate power supply along with frequent breakdowns of power supply in the early part of the 90s and sharp increases in the prices of power in the later years, and inadequate industrial investment.

The growth rate of manufacturing output has increased sharply since 1999-00; the average growth rate of the manufacturing sector over the five years has been 9.4 and the large and small scale industries growth rates have been 10.9 and 6.3 percent respectively. The growth rate has accelerated despite low levels of investment because of the demand stimulus in the form of credit for the purchase of consumer durables and a sharp increase in exports after the quota restrictions were removed.

\section{Structural Problems Confronting the Manufacturing Sector}

The performance of the manufacturing sector in Pakistan has been marred by a number of factors. These problems may broadly be grouped into industrial and trade policy distortions, a narrow industrial base, low productivity levels, poor quality of products, the role of public sector enterprises, higher costs of production, problems in the regulatory framework, and weak infrastructure.

\section{Industrialization Strategy and Pattern of Demand}

Pakistan has all along pursued the Import Substitution Industrialization Strategy' but there has been little diversification of the industrial structure. The cascaded tariff structure has provided higher protection to consumer goods with adverse implications for growth of capital goods and intermediate goods industries.

Import substitution accounted for 96.9 percent of growth during the 1951-55 period and for 25 percent during the 1963-71 period. Import substitution accounted for a very small proportion of growth in the later years because producers did not venture into new import substitution industries and continued with the traditional import substitution industries. Since 1955 domestic demand has accounted for roughly three-fourths of the growth and exports have contributed roughly 25 percent to growth. Therefore, any slow down in domestic demand and exports affect manufacturing output adversely. It may be noted that demand stimulus coming from imports and loans for the purchase of consumer durables have

\footnotetext{
${ }^{5}$ The policy has an anti-export bias in trade policies and thus badly affects the growth of exports.
} 
been mainly responsible for the sharp growth in industrial output over the last few years.

Table-3: Sources of Manufacturing Growth

\begin{tabular}{cccc}
\hline Period & $\begin{array}{c}\text { Domestic } \\
\text { Demand }\end{array}$ & $\begin{array}{c}\text { Export } \\
\text { Expansion }\end{array}$ & $\begin{array}{c}\text { Import } \\
\text { Substitution }\end{array}$ \\
\hline $1950-51$ to $1954-55$ & 2.4 & 1.8 & 96.6 \\
$1954-55$ to $1959-60$ & 53.1 & 24.0 & 22.9 \\
$1959-60$ to $1963-64$ & 95.7 & 4.6 & -0.3 \\
$1963-64$ to $1970-71$ & 60.0 & 15.0 & 25.0 \\
$1980-81$ to $1988-89$ & 79.7 & 10.2 & 10.1 \\
$1988-89$ to $1991-92$ & 60.4 & 37.9 & 1.7 \\
$1991-92$ to $2000-01$ & 77.8 & 22.9 & -0.8 \\
$1991-92$ to $1995-96$ & 84.1 & 16.1 & -0.1 \\
$1995-96$ to $2000-01$ & 73.6 & 27.6 & -1.2 \\
\hline
\end{tabular}

Source: Khan (1964), Lewis (1970), Kemal (1990, 1993) and Present study estimates.

While trade policy reforms in recent years have exposed domestic enterprises to international competition, these enterprises continue to suffer from the legacy of import substitution and have yet to re-position themselves to compete effectively in the global market. Furthermore, the trade policy still has an import substitution bias for certain critical sectors such as automobiles, whose imports are subject to tariff peaks. The continued protection to these sectors has not helped these enterprises to become globally competitive. It must, however, be recognized that protectionist policies may not be a viable strategy in the emerging multilateral trading system.

While Pakistan has successfully divested a large number of industrial units it has not always resulted in higher levels of efficiency because of the monopolistic tendencies in the economy. It has led to cartelization with low levels of output and higher price levels. How to ensure maximum output after privatization by means of a proper regulatory framework is one of the major issues. 


\section{Industrial Productivity}

Whereas the growth rate of the manufacturing sector has been quite impressive, value added in this sector is grossly over stated due to distortions in the system. If value added in the manufacturing sector is evaluated at world prices, its contribution to GDP is relatively much smaller, reflecting gross inefficiencies and/or excessive profits. Even in 1991 when some of the distortions had already been removed, more than 30 percent of value added could be ascribed to protection. ${ }^{6}$

Efficiency levels varied significantly across different manufacturing industries: some industries were so efficient that domestic resources were only a fraction of their valued added and were generally penalized, while some were so inefficient that value added was negative at world market prices and survived because of rather heavy protection. Whereas average $\mathrm{DRC}^{7}$ for consumer goods industries was 6.00 , for intermediate and capital goods industries it was 0.22 and 0.82 , respectively. Similarly, compared to the average DRC of 1.20 for the large-scale industries it was 1.49. Moreover, the DRCs for export-oriented and import-competing activities have been 0.54 and 2.15 . It shows that tariff rationalization that gives a level playing field to import substitutes and export oriented industries and to consumer, intermediate, and capital goods industries would help in improving the efficiency of the manufacturing sector.

To sustain the competitiveness in the activities where the country has a comparative advantage and attain comparative advantage in those that at present it does not have, growth rates of productivity need to be higher than that of competitor countries. During the period 1992-2001, labor productivity in the manufacturing sector grew at a rate of 2.2 per cent, which though higher than that of Bangladesh and India is lower than that of other countries, such as Sri Lanka, Republic of China (Taiwan), and Korea.

\footnotetext{
${ }^{6}$ Since 1991 a number of initiatives have been taken to reduce the level of protection, the maximum import duty now stands at $25 \%$. To determine the extent to which it has resulted in a reduction in effective protection and improved efficiency levels, an industry - wide survey is required. No such study has been undertaken for the last 15 years.

${ }^{7}$ These estimates refer to 1991, reported in Kemal, Mahmood, and Ahmed (1994).
} 
Table-4: Annual average Labor Productivity Growth (\%): 1992-01

\begin{tabular}{lc}
\hline \multicolumn{1}{c}{ Country } & Growth rate of labor productivity \\
\hline Pakistan & 2.23 \\
Bangladesh & 1.98 \\
Sri Lanka & 2.68 \\
India & 1.56 \\
Republic of China & 3.39 \\
Malaysia & 3.37 \\
Korea & 7.55 \\
\hline
\end{tabular}

Source: APO, Asian Productivity Data \& Analysis 2003. Asian Productivity Organization, Tokyo

Labor productivity is only a partial measure of productivity; total factor productivity ${ }^{8}$ (TFP) that takes into account the other factors of production is a superior measure. A comparison of the growth of total factor productivity shows that except for the Republic of China, Pakistan experienced higher TFP over a longer period compared to the neighboring countries [see Table-5].

Table-5: Total Factor Productivity

\begin{tabular}{lcc}
\hline & Country & Growth rate of labor productivity \\
\hline Pakistan & $(1964-2001)$ & \\
Bangladesh & $(1960-85)$ & 0.33 \\
Sri Lanka & $(1960-85)$ & 1.25 \\
India & $(1960-85)$ & 0.72 \\
Republic of China & $(1960-94)$ & 2.00 \\
Malaysia & $(1960-94)$ & 0.90 \\
Korea & $(1960-94)$ & 1.50 \\
\hline
\end{tabular}

Source: Kemal et. al. (2000), "Pakistan Country Report", Global Research Project.

\footnotetext{
${ }^{8}$ Growth in total factor productivity is part of the value-added growth not explained by the increase in factor inputs.
} 
For the period 1964-65 to 2000-01, total factor productivity (TFP) in the manufacturing sector grew at a rate of 3.21 percent (Table-6). We may note that the sharp increase in the growth of productivity in the manufacturing sector shows a high degree of inefficiency in the sector in the base year reflected in the very high DRC estimates for the earlier years. For example DRC was 3.31 in $1980-81$ which declined to 1.20 by $1990-91$.

Table-6: Trends in Total Factor Productivity in Manufacturing Sector

\begin{tabular}{ccccc}
\hline \multirow{2}{*}{ Sector } & \multicolumn{3}{c}{ Growth Rates } & \multirow{2}{*}{ TFP } \\
\cline { 2 - 4 } Period & Value Added & Capital & Labor & \\
\hline $1964-65$ to $2000-01$ & 6.39 & 2.23 & 0.94 & 3.21 \\
$1964-65$ to $1969-70$ & 8.99 & 2.96 & 1.78 & 4.26 \\
$1970-71$ to $1979-80$ & 5.48 & 2.04 & 1.43 & 2.01 \\
$1980-81$ to $1989-90$ & 8.09 & 2.10 & 0.61 & 5.38 \\
$1990-91$ to $2000-01$ & 3.99 & 2.09 & 0.25 & 1.64 \\
\hline
\end{tabular}

Source: Authors own calculations using data from Pakistan Economic Survey, various issues.

TFP growth in the manufacturing sector exceeded 4 percent in the 1960 s and 5 percent in the 1980s. In the 1960s, TFP improved mainly to learning-by-doing with improved export competitiveness in the 1960s and in the 1980s due to de-regulation, privatization, and liberalization of imports in the 1980s. On the other hand low growth of productivity may be attributed to nationalization policies in the 1970s and to slow embodied technical change resulting from low and falling levels of investment and low capital utilization due to slackness in domestic and world demand in 1990s.

Even though total factor productivity growth rate in Pakistan has been quite high it reflects the low efficiency levels in the base year rather than improvements in productivity resulting from technical change. Moreover, because TFP in other countries has also increased it might not have impacted the productivity differentials. The main sources of productivity growth, in particular human resource development, R\&D activities, and engineering industries that provide machinery in accordance with the factor endowments of the country, have received relatively less attention in Pakistan and growth rates of productivity can be sustained provided these activities are promoted. 
Table-7: Human Resource Development Activities: 2001

\begin{tabular}{lcccc}
\hline Country & $\begin{array}{c}\text { Expenditure } \\
\text { on education } \\
\text { (\% of GDP) }\end{array}$ & $\begin{array}{c}\text { Expenditure } \\
\text { on health } \\
\text { (\% of GDP) }\end{array}$ & $\begin{array}{c}\text { R\&D } \\
\text { Personnel } \\
\text { (thousands) }\end{array}$ & $\begin{array}{c}\text { R\&D } \\
\text { expenditure } \\
\text { (\% of GDP) }\end{array}$ \\
\hline Bangladesh & 4.02 & 0.90 & - & - \\
China & 6.19 & 5.77 & 138.4 & 2.16 \\
India & 3.45 & 0.93 & 308.39 & 0.62 \\
Indonesia & 0.09 & 0.22 & - & 0.05 \\
Iran & 4.30 & 1.51 & 0.73 & 0.64 \\
Japan & 4.71 & 1.89 & 1000.01 & 3.29 \\
Korea & 6.50 & 2.63 & 178.94 & 2.96 \\
Malaysia & 7.13 & 2.22 & 23.26 & 0.82 \\
Pakistan & 1.60 & 0.70 & 16.20 & 0.20 \\
Philippines & 3.53 & 3.43 & 25.16 & 0.15 \\
Singapore & 3.95 & 0.88 & 24.88 & 2.13 \\
Sri Lanka & 2.44 & 1.37 & - & 0.03 \\
Thailand & 4.03 & 1.59 & - & 0.12 \\
Vietnam & 3.19 & 0.87 & - & 0.34 \\
\hline
\end{tabular}

Source: APO (2003).

Note: For Iran, Japan, and the Philippines, the education and health estimates refer to 2000 . The health estimates of Korea also refer to 2000. R\&D personnel data for India refers to 1998, that of Malaysia and Pakistan to 2000, and of the Philippines and Thailand refer to 1996. The R\&D expenditure estimates for India. Malaysia, Pakistan, refer to 2000 and of Thailand to 1999.

\section{Lack of Diversification}

A broad based industrial sector is essential for exploiting the opportunities offered by globalization, but Pakistan's industrial structure lacks diversification; in 2000-01, almost 38 percent of industrial value added was contributed by food and textiles (Table-8). In the dynamic areas comprising electronics, machinery, and metal products, Pakistan has hardly made any progress, while the engineering sector is dominated by either assembly operations based on imported parts, or the production of basic and simple 
components. Furthermore, Pakistan has not been able to develop a strong capital goods sector: the share of the engineering industries in total manufacturing is around 5 percent. Not surprisingly, a narrow industrial base has led to highly concentrated exports: roughly 80 percent of the country's manufactured exports consist of only textiles and clothing and carpets and rugs.

Table-8: Percent Share of Value Added in Various Industries.

\begin{tabular}{|c|c|c|c|c|c|c|c|c|}
\hline No. & Industry Classification & 1955 & $\begin{array}{l}1959- \\
1960\end{array}$ & $\begin{array}{l}1970- \\
1971\end{array}$ & $\begin{array}{l}1980- \\
1981\end{array}$ & $\begin{array}{l}1990- \\
1991\end{array}$ & $\begin{array}{l}1995- \\
1996\end{array}$ & $\begin{array}{c}2000- \\
2001 \\
\end{array}$ \\
\hline 1 & Food Manufacturing & 8.41 & 8.56 & 16.24 & 20.12 & 14.05 & 15.19 & 13.77 \\
\hline 2 & Beverage Inc & 0.36 & 0.36 & 0.75 & 1.82 & 1.40 & 1.59 & 1.55 \\
\hline 3 & Tobacco & 4.18 & 5.29 & 10.88 & 13.26 & 6.35 & 6.18 & 7.41 \\
\hline 4 & Textiles & 45.52 & 42.61 & 30.31 & 15.93 & 26.35 & 22.31 & 24.02 \\
\hline 5 & $\begin{array}{l}\text { Footwear and other wearing } \\
\text { appare1 }\end{array}$ & 2.57 & 2.06 & 0.44 & 1.68 & 1.82 & 1.87 & 2.82 \\
\hline 6 & $\begin{array}{l}\text { Leather and leather } \\
\text { products except footwear } \\
\text { and wearing apparel }\end{array}$ & 1.04 & 0.83 & 1.18 & 1.06 & 1.09 & 0.78 & 1.47 \\
\hline 7 & Paper and paper products & 1.92 & 2.20 & 1.63 & 1.48 & 1.57 & 1.61 & 1.57 \\
\hline 8 & $\begin{array}{l}\text { Printing, publishing and } \\
\text { allied industries }\end{array}$ & 2.63 & 2.39 & 1.66 & 0.75 & 2.26 & 2.01 & 0.32 \\
\hline 9 & $\begin{array}{l}\text { Chemical and chemical } \\
\text { products * }\end{array}$ & 6.65 & 8.68 & 10.99 & 12.31 & 15.04 & 16.26 & 15.17 \\
\hline 10 & Rubber & 0.39 & 0.35 & 1.32 & 0.97 & 0.96 & 0.88 & 0.37 \\
\hline 11 & $\begin{array}{l}\text { Other Non-metallic mineral } \\
\text { products }\end{array}$ & 2.80 & 4.55 & 3.39 & 5.91 & 6.62 & 7.15 & 7.45 \\
\hline 12 & Basic Metal Industries & 2.06 & 2.53 & 2.41 & 4.03 & 5.56 & 4.18 & 4.27 \\
\hline 13 & $\begin{array}{l}\text { Fabricated metal products } \\
\text { except machinery and } \\
\text { transport equipment }\end{array}$ & 2.50 & 3.89 & 1.75 & 1.06 & 0.86 & 0.69 & 1.15 \\
\hline 14 & Machinery except electrical & 1.22 & 2.11 & 0.96 & 1.71 & 2.52 & 1.61 & 1.11 \\
\hline 15 & $\begin{array}{l}\text { Electrical machinery } \\
\text { apparatus, appliances and } \\
\text { supplies }\end{array}$ & 0.82 & 1.85 & 3.61 & 3.47 & 4.11 & 7.67 & 3.28 \\
\hline 16 & Transport equipment & 1.10 & 2.94 & 2.59 & 2.47 & 2.59 & 3.50 & 4.66 \\
\hline 17 & Other Industries & 15.81 & 8.80 & 9.89 & 11.96 & 6.83 & 6.51 & 12.43 \\
\hline
\end{tabular}

Source: Census of Manufacturing Industries, Various Issues.

Note: *Sum of headings 'drugs and pharmaceutical...', 'industrial chemicals' and 'other chemical products'. 


\section{The Role of the Public Sector}

Though the role of the public sector has been drastically curtailed as a result of deregulation and privatization policies, some industries continue to be dominated by state owned enterprises. Some of these enterprises produce primary raw materials and intermediate inputs and as a result the inefficiencies of the public sector have an adverse impact on downstream industries. For example, the inefficiencies of Pakistan Stee1 have been the major stumbling block to engineering industries. Now that it has been privatized one hopes that efficiency levels will increase resulting in a decline in prices. Since there is only one steel mill and the new steel mill recently inaugurated also belongs to the same owner, the producer may exploit the monopoly power and increase the prices of basic steel. There is a need to regulate the supplies through liberal import policies that allows duty free imports of steel. Similarly, engineering industries in the public sector make investment expensive. The remaining public enterprises in the manufacturing sector should be divested but with the clear understanding that the import duties on such products would be rationalized.

\section{Smuggling and Higher Cost of Domestic Production}

There is widespread smuggling and that has adversely impacted the growth of many industries, especially consumer durables. Domestic producers cannot compete with smuggled goods because import duties on raw materials and intermediate goods have been high. In recent years tariff rationalization has been instrumental in the growth of consumer durables but more tariff rationalization is necessary and there is a need for a long run policy.

Whereas the investment policy of 1997 clearly lays down fiscal incentives to various industries there is a need to ensure that protection to various economic activities and fiscal incentives reinforce each other. In particular, the incentive structure has to be reformed in such a way that it promotes dynamic comparative advantage.

The cost of domestic manufacturing is elevated due to a number of factors including higher power and energy prices, labor levies that lead to an increase in effective wage rates, high rates of sales taxes, and a high degree of corporate and income taxation. 


\section{Regulatory and Legal Environment}

Though Pakistan has strived to improve the overall business climate and accordingly her ranking in terms of de-regulation has improved, weaknesses still remain in the regulatory and legal framework. Businessmen still have to comply with a host of regulations relating to the work environment including health and sanitation, product standards, taxation, etc. Excessive discretionary powers in the hands of the enforcing agencies often lead to harassment of enterprises and opens up avenues for corruption resulting in the loss of business confidence. To develop a viable industrial sector, there is a need to put in place a regulatory and legal environment that is conducive for private businesses. In particular the tariff regime must be put in place for over a longer period to allow producers to take long run decisions with confidence. We may note that a lack of continuity in policies has been the major stumbling bloc to increased investment. Even though over the last 5 years the government has not taken any decision that adversely affects the profitability of investors, investors are still reluctant to invest.

\section{Financial System}

A well-functioning financial system is essential for industrial development and growth because it efficiently channels investible funds to the most productive uses. A series of measures adopted in recent years have led to improvements in the financial system but the spread between the deposit and lending rate is still unacceptably high. Better appraisal and the strict implementation of prudential regulations seem to have resulted in lower infected portfolios of the banks, but so far have not resulted in a low spread.

The availability of credit to the private sector has increased in recent years both because of an increase in the liquidity and a decline in the fiscal deficit resulting in lower levels of credit for budgetary financing. This had led to low rates of interest. However, liquidity has been somewhat reduced and the budgetary deficit has increased resulting in higher rates of interest. The changing levels of interest rates also result in lower levels of investment.

\section{Foreign Exchange Market}

Pakistan is following a system of floating exchange rates. However, the State Bank of Pakistan intervenes and does not allow market forces to operate. For example, the inflation rate for a second year is running at 
around 9 percent but the par value of the rupee to the dollar has not changed. While the lower value of the dollar against the rupee keeps down the cost of imports and promotes investment it also hurts exports. Since exports have been one of the major contributory factors to the growth process, a proper exchange rate assumes great significance.

\section{Weak Infrastructure}

Weak physical infrastructure has been a major factor hindering the performance of the manufacturing sector. Whereas the lack of repair and maintenance has resulted in the deterioration of physical infrastructure, inefficiencies in the public sector utilities have contributed to high costs of production, thus eroding the competitiveness of domestic manufacturers.

\section{Power Supply}

Despite efforts to encourage efficient utilization of energy resources, the technical, financial, and operational efficiency of the power sector has continued to deteriorate resulting in costly yet unreliable power supply. According to a survey conducted by the World Bank ${ }^{9}$, the majority of respondents identified problems related to power supply as a major obstacle to business expansion. It is estimated that a typical business in Pakistan on average loses $5.6 \%$ percent of annual output due to power outages as compared with less than $2 \%$ for the average plant in China. In order to minimize downtime caused by problems in power supply, firms are often forced to use their own generators. It has been estimated that the use of generators on average ties up capital of a firm up to about 12 percent of its fixed assets. To make the situation worse, businesses often experience delays in getting power connections. For instance, according to the World Bank (2003), the average waiting period for a business to obtain a power connection is 45 days in Pakistan as against only 15 days in China.

\section{Telecommunication Services}

Though the quality of telecommunications has improved in recent years, there is still room for further progress in terms of improvement in efficiency and expansion of fixed line connections. The privatization of PTCL and competition in wireless and mobile telephones has improved the situation significantly. With the advancement in information technology, businesses all over the world are increasingly relying on the internet for communication purposes and carrying out their business activities. While

\footnotetext{
${ }^{9}$ World Bank (2003), "Improving the Investment Climate in Pakistan".
} 
the usage of the internet in Pakistan is on the rise, poor connectivity and slow speed continue to be major problems.

\section{Transport}

An efficient transport network is vital for economic development. In Pakistan, the transport sector is incurring heavy asset losses due to the inadequate maintenance of existing facilities. The unsatisfactory state of the transportation network has imposed enormous costs on the economy: according to a recent estimate, inefficiency in transport alone is reckoned to cost the economy Rs.320 billion a year. ${ }^{10}$

Road transport is the dominant mode, but the current state of roads is far from satisfactory. Lack of repair and maintenance of existing roads has resulted in the rapid deterioration of the road network. It is estimated that $70 \%$ of the national road network is in "fair to poor" condition, whereas $90 \%$ of the provincial network in Punjab is rated as "fair to poor". Poor road conditions not only lead to delays but also result in excessive wear and tear of transport vehicles contributing to high transportation costs.

The railways that are cost effective for long haul trafficking suffer from inefficiencies. Due to higher costs of alternative transportation modes, the bulk of the freight is handled by the trucking industry resulting in overuse of the road network. The quality of air and shipping services is marginally better but costs are high due to lack of competition. The freight handling costs at the ports in Karachi and Qasim are reckoned to be several times higher than those of comparable ports in the region. Furthermore, upcountry industrial centers are particularly at a disadvantage as they face even higher costs of transportation of raw materials and other inputs from the Karachi port.

\section{Human Resource Development}

Pakistan is deficient in the skilled human resources that are vital for technological advancement. More specifically, the quality of scientific manpower produced in the educational institutions is poor due to a number of factors including a lack of highly qualified professional teaching staff. Moreover, because of higher returns elsewhere the best students are not opting to pursue careers in science and technology. Furthermore, the skills imparted in various polytechnics and the vocational institutions are not demand driven and resultantly most of the skilled workers that graduate

\footnotetext{
${ }^{10}$ World Bank (2002) Pakistan Trade Sector Assistance Strategy Note, June 2002.
} 
from these institutions fail to get a job. The productivity of various industries is adversely affected due to lack of skilled workers and some of the industries are not established because of the lack of requisite skilled workers. In order to build a sound and diversified production structure in the industrial sector, Pakistan needs to attach high priority to human resource development.

\section{Science and technology}

In a rapidly changing international economic environment, science and technology is vital for sustaining the development momentum. Unfortunately, the state of science and technology has been far less satisfactory in Pakistan as compared with other emerging economies. Pakistan lacks strong engineering foundations and the loss of qualified personnel has further hindered the development of the country's technological base. The poor state of science and technology may also be attributed to the relatively low awareness of technological needs and capacity of the domestic industries, the weak link between industry, academia, and research institutions, and a lack of resources for scientific research and technological development. To prepare the country to face emerging challenges, the development of science and technology and its interface with industry has to be brought to the forefront of the industrial vision for the future. While some work has been initiated recently, it is just the tip of the iceberg.

\section{Skill Development}

The labor market in the country can be characterized by a shortage of middle-level skilled personnel and unemployment of educated persons. The availability of skilled manpower is essential for raising productivity levels as well as achieving industrial diversification. Whereas the relative neglect of technology based industries such as engineering and chemicals and very little consideration for the quality of products may have created low demand for skilled workers, the supply of skilled workers has also been inadequate even to meet the demand that was generated. Since Pakistan intends to move towards high-tech industries and the world is changing in such a way that export orientation will be the only viable strategy, the quality of products will have to be improved significantly. This is possible provided there is an improvement in skill composition. In the absence of trained manpower the producers will make informal arrangements leading to sub-optimal decisions, low levels of productivity, and the loss of output. 
The formal institutional system produces a very small proportion of skilled and semi-skilled workforce. Even more importantly, the trained workforce in the public sector institutions are not preferred by the entrepreneurs as they tend to believe that such training is not very useful. The poor ranking of polytechnic and vocational institutions by the producers reflect the fact that skills imparted fall short of the requirements of the producers.

The main beneficiaries of skills improvement are the producers themselves whose output, productivity, and profits are expected to go up. However, despite dearth of skills, very little effort has been made by producers to improve the skills of workers. It needs to be underscored that it would be counter-productive for a single producer to initiate such training as he may not get the benefit because workers can move to other producers. A cooperative effort on the part of the industrialists with active support from the government would be required for setting up such institutions. The institutions for specific industries would help in training in the relevant fields and to the satisfaction of producers.

\section{Industrial Vision and Industrial Policy Parameters}

While performance of the manufacturing sector of Pakistan was much better compared to other South Asian countries up to the 1980s, her performance in the 1990s has been less than adequate and it has been fractional compared to South East Asian countries. No doubt in recent years, the manufacturing sector has performed well but as pointed out earlier sustainability is the issue. Pakistan has to make important strategic choices to ensure sustainable growth in the manufacturing sector. These choices are to be taken in a rapidly changing international arena characterized by:

- Shortening Product Life cycles: The nature of technological innovation and consumer demand has created an environment for new products whose lifecycles are relatively shorter than before. Therefore, only those producers who remain competitive through heightened applications, innovation, and quick responses to consumer demands will be able to survive.

- A More Complex Global Marketplace: There has been a change in the demand patterns towards sophisticated consumer products. Traditional products such as food and textiles account for a very small proportion of consumption in the developed world. Moreover, even for the traditional products the consumers have preferences for standardized and quality products. 
- Emerging New Industrial Patterns: The vertically integrated industrial patterns within the country may be replaced by network arrangements among firms across countries. Intra-industry trade, especially in components and parts, has increased sharply over time.

- Changing Requirements for Economic Infrastructure: An increasingly wider array of occupational skills is required to compete effectively. Similarly, information technology and logistics have become part of the basic infrastructural framework for industrial development.

- A New Global Trading Regime: With the advent of the World Trade Organization, production structures are influenced by the various agreements and countries have become interdependent. The governing methods, legislations, and trading relationships are to influence the manufacturing structures of each country.

- New Patterns of Geographic Division of Labor: Whereas W'TO calls for multilateral trading arrangements there have been movements towards regionalism and more recently FTAs with various countries.

In view of the above considerations, Pakistan can no longer afford to have a protected, inefficient, and concentrated manufacturing sector. It must ensure dynamic, efficient, diversified, and rapidly growing manufacturing activities that help in generating maximum value added and employment. The country must specialize in accordance with her dynamic comparative advantage, create a niche market for herself in various products and countries, and "Made in Pakistan" should be a symbol of quality and standardized products. For the realization of these objectives, Pakistan would have to strengthen the value addition process through backward and forward linkages and increasing the productivity levels emanating from human resource development, technical and vocational training, and research \& development.

The demand pattern all over the world has changed towards sophisticated consumer products and standardized quality traditional products. As a result, lifecycles of various technologies have become relatively shorter and only those producers who innovate will be competitive in the world market. Industrial organization has changed as well; vertically organized industrial patterns of the past are being replaced by network arrangements among firms within and outside the country. Intra-industry trade especially in components and parts has increased sharply over time. An increasingly wider 
array of occupational skills including information technology and logistics has become part of the basic infrastructural framework for industrial development. With the advent of the World Trade Organization, like many other developing economies, Pakistani industries are also undergoing restructuring. Besides, strict implementation of intellectual property rights would significantly reduce the possibilities of reverse engineering.

The strategy of industrial development should comprise the provision of a level playing field for domestic and foreign investors and for small and large scale producers. Manufacturing growth may be based on private sector participation and the role of the government is restricted to the provision of the necessary physical, social, technological and financial infrastructure and regulatory frameworks. Augmenting the science and technology apparatus of the private sector, bringing research institutions up to international standards, and the streamlining of technology creation, absorption and diffusion systems are essential if Pakistan wants to diversify her production towards new technology based industries. Towards this end, foreign direct investment would be rather helpful.

The MTDF calls for a knowledge economy and that requires the development of science and technologies, R\&D institutions, and skill development. Manpower development programs need to be expanded, and the human development policies outlined by the government need to be effectively implemented. Whereas adequate financing has been assured for S\&T organizations for their research programs, a more conducive environment has been prepared to attract and retain good scientists and technologists through an appropriate reward and incentive system and proper facilities. Linkages among local $R \& D$ agencies and the local system with the international community will be intensified.

It is necessary to nurture university research to continuously feed the R\&D system including research institutes with fresh minds and qualified manpower and reduce reliance on imported expertise and foreign training. The government policy should be: that universities are provided with better laboratory facilities and libraries and are made the focal points of research and active collaboration with applied research organizations, recognition and reward for scholarly excellence, establishment of new research institutes, involvement of the Ministry of Science and Technology with bodies administering scientific and technical educational institutions, identifying specific research projects to be undertaken at universities, encouraging the private sector to establish universities of science and technology that offer attractive working conditions to well qualified teaching and research staff, and the establishment of an Institute of Science and Technology (ISATOP) 
that will adopt and maintain standards comparable to the best in the world. Industry will be encouraged to utilize indigenous technologies and products through appropriate tariff reforms. Increased competition, both internal and external, will be introduced so that industry realizes the need for increased efficiency and productivity, which can only be fulfilled by a strong R\&D sector.

All these are important initiatives and sufficient resources need to be allocated and efficiently used for improved scientific and technological manpower. The private sector needs to be inducted and the government should provide tax incentives to the firms that invest in skill development and R\&D.

\section{Industrial Clusters, Industrial Cities and Zones}

Whereas clusters may themselves become established, or foreign firms establish clusters because of the availability of infrastructure, the government may also set up clusters by developing vertical and horizontal relationships amongst firms. Clusters having critical mass can help in sharing knowledge and resources and stimulating creativity, innovation, and entrepreneurship. Sustained competitive advantage can be produced by mutual support and the coordinated development of demand, competition, factor availability, and support to industries. We may note that good clusters include rich technical resources and its distribution media, human resource with high adaptability and organizations for development and training, abundant financial resources, well-developed infrastructure for software and hardware, and fair-scale groups of customers with discriminatory ability.

Clusters are most important for SMEs because they provide costeffective opportunities to deliver targeted technical assistance for the upgrading of technology, management, and marketing. Clustering leads to greater efficiency and flexibility not attainable by individual firms operating in isolation.

\section{Common Facility Centers}

By introducing new technology, the production of better quality goods and higher productivity levels, Common Facility Centers enable industry to compete in terms of price and quality both in the local market as well as in foreign markets. Since micro, small, and medium enterprises neither have the knowledge nor the resources to acquire new technology, the government must initially set up such centres but eventually they should be transferred to the private sector. These centres can provide testing 
facilities and extend advisory services for higher productivity with standardization to the sub-contractor. Support centres help in gaining greater competitive strength and develop collective efficiencies; providing common services to improve forward and backward linkages with markets and with suppliers of inputs; cooperation between firms in upgrading technology; organizing consultative meetings and disseminating information; development of sub-sector business associations to provide leadership and coordination; provision of essential machining facilities, which should be need based; and forging links between enterprises and the research and technological development being undertaken in institutions of higher learning and publicly financed research centers.

\section{Incubators}

Incubators may be technology based to ensure proper commercialization of their research products and linked to universities and research institutions or they may be industrial incubators for developing small businesses as vendors for components and services. The government may provide the necessary support to the incubator in the form of low or no rent and an operating subsidy, until rents and fees from the tenants match operating expenses. Thus the business incubator itself runs as a business, with the prospects of becoming self supporting when operations are fully established.

\section{Certification}

Certification is the key to obtaining the benefits of quality improvements. Without proper certification, exports of food, chemicals, and components, are inconceivable. The certification has to be credible and any indigenous certification agency should have counter certification. Joint ventures with reputed accredition agencies around the world would help in not only increasing total volume of exports but also higher unit values leading to an increase in the value of total exports.

\section{Skill Development}

The manpower policy should reflect the proper and efficient use of the talents and abilities of individual workers, so that they get satisfaction from their jobs, thus contributing to the development of the economy. The need to develop and upgrade the ability of workers is crucial in this era of change, which is reflected by the ever-changing industrial structure, technological innovations, and increasing shortages of skilled workers. Vocational training is not only a means to help workers to earn their living, 
develop their abilities, and obtain higher grade jobs, it is also critical for expanding the volume of production and the national income, as well as for raising productivity and the yield on invested capital.

Vocational training can only produce results if it meets the demands of the labor market, which in turn are governed by the needs of the economy as a whole. Training does not create employment; rather it is the state of the labor market that determines the volume and standard of training. Like the economy itself, vocational training should be sufficiently flexible to keep up with changes in production techniques. It is a continuous process which evolves along with the national economy, the techniques of each industry, and the working life of the individual workers.

Skilled manpower resources have to be made available so that the development programs of the country can be effectively implemented. The development of an efficient vocational system at all levels is most urgent. The system should aim at making the best use of limited resources and providing skilled manpower according to the requirements of the labor market in the country. It is essential that the system has a mechanism for regular built-in monitoring and feedback so that manpower planning can effectively respond to the changing demands of the economy. It is also necessary that the private sector be fully involved in determining manpower policies and the vocational training system, because ultimately it is their needs that have to be met. The private sector, therefore, must come forward and advise the government on the requirements in the labor market and wherever possible, assist the public sector in financing vocational training programs.

The private sector should be encouraged to expand its involvement in skills training. Greater access to credit, exemptions of import duties on training equipment by certified institutions and agencies, could be offered as incentives. There may be public-private partnerships where the government provides seed money. However, it is important to ensure proper regulation through the determination of appropriate levels of fees, conduct of proper examinations, and the establishment of proper certification procedures.

\section{Infrastructure Development}

Since Pakistan has planned double digit growth for the manufacturing sector, the infrastructure requirements have increased manifold. Industrial estates need to be established and the Medium Term Development Framework (MTDF) calls for a number of industrial estates along with motorways, highways and railways. The transport plan outlined 
in the MTDF should be sufficient to meet the entire transport demand. Similarly, expansion in the telecommunication activities would imply that producers will not have to suffer from communication problems.

The government of Pakistan has approved a long run energy plan that focuses on renewable resources and domestic resources. However, power rates need to be rationalized. It needs to be noted that a reduction in power rates is absolutely essential for the development of various manufacturing sectors especially chemicals and the engineering sectors. The government will have to introduce bulk buying rates for the manufacturing sector with a view to reducing the cost of production in this sector.

\section{Conclusions}

The growth of the large scale manufacturing sector at the rates of 14.1 and 12.5 percent in 2003-04 and 2004-05 has created the euphoria of high growth rates over the long run. Since investment rates have been fluctuating around a low level, the projected sustained growth of the manufacturing sector seems to be quite ambitious. Moreover, the manufacturing sector is suffering from various structural problems including lack of diversification, allocative, technical and X-inefficiencies, poor quality of products, and low levels of R\&D activities resulting in slow growth rates of productivity, making Pakistani products uncompetitive in the world market.

Whereas Pakistan has all along pursued the Import Substitution Industrialization Strategy, it has failed to diversify the industrial structure because producers did not venture into new import substitution industries and continued with the traditional imports substitution industries. Domestic and foreign demand has been the major contributory factor to the growth of the manufacturing sector. While credit for consumption can stimulate demand, it may have serious implications for investible funds. It underscores the need for taking suitable measures for the acceleration of the growth rate of exports.

Widespread smuggling has adversely impacted the growth of many industries especially consumer durables. Domestic producers cannot compete with smuggled goods because the import duties on the raw materials and intermediate goods have been high. In recent years, tariff rationalization has been instrumental in the growth of consumer durables but further tariff rationalization is necessary and there is a need for a long run policy. Some of the other factors that tend to increase the cost of production include higher power and energy prices, high transport costs, 
increases in wage rates as a result of labor levies, high rates of scale taxes and a high degree of taxation. Moreover, businesses still have to comply with a host of regulations relating to the work environment including health and sanitation, product standards, taxation, etc. Excessive discretionary powers in the hands of the enforcing agencies often lead to harassment of enterprises and opens up avenues for corruption resulting in the loss of business confidence.

The poor state of science and technology may also be attributed to the relative lack of awareness of technological needs and capacity of domestic industries, the weak link between industry, academia, and research institutions and lack of resources for scientific research and technological development. To prepare the country to face emerging challenges, the development of science and technology and its interface with industry has to be brought to the forefront of the industrial vision for the future. While some work has been initiated recently, it is just the tip of the iceberg.

Sustained competitive advantage can be produced by mutual support and coordinated development. Clusters play an important role in improving competitiveness. Common Facility Centers provide testing facilities and extend advisory services for higher productivity with standardization to the sub-contractor. Incubators also help in improving the technological levels of various industries. Similarly, certification would play an important role in exports.

Vocational training that provides skilled manpower according to the requirements of the labor market in the country contributes significantly to the growth of manufacturing industries. The private sector should be encouraged to expand its involvement in skills training. Greater access to credit, exemptions on import duties on training equipment by certified institutions and agencies could be offered as incentives. There also may be public-private partnerships where the government provides the seed money. 


\section{References}

Government of Pakistan, 1997, 50 Years of Pakistan in Statistics (1947-97) Volume I Summary, Federal Bureau of Statistics.

Government of Pakistan, Census of Manufacturing Industries, Various Issues, Federal Bureau of Statistics, Islamabad.

Government of Pakistan, 2005, The Medium Term Development Framework: 2005-10, Planning Commission, Islamabad.

Kemal, A. R., Muslehuddin and Usman Qadir, 2002, Global Research Project: Pakistan Country Report Presented at GRP Workshop in Dhaka.

Kemal, A. R., Z. Mahmood, A, M. Ahmad, 1994, Structure of Protection, Efficiency, and Profitability, Vol. 1.

Khan, A., 1964, Import Substitution, Export Expansion and Consumption Liberalisation, Pakistan Development Review, Autumn.

Lewis, S., 1970, Pakistan: Industrialization and Trade Policies, Paris: OECD.

World Bank, 2003, Improving the Investment Climate in Pakistan, 2003. 